\title{
Chryseobacterium formosense sp. nov., isolated from the rhizosphere of Lactuca sativa L. (garden lettuce)
}

\author{
Chiu-Chung Young, ${ }^{1}$ Peter Kämpfer, ${ }^{2}$ Fo-Ting Shen, ${ }^{1}$ Wei-An Lai ${ }^{1}$ \\ and A. B. Arun ${ }^{1}$ \\ ${ }^{1}$ College of Agriculture and Natural Resources, Department of Soil and Environmental \\ Sciences, National Chung Hsing University, Taichung, 402, Taiwan, Republic of China \\ ${ }^{2}$ Institut für Angewandte Mikrobiologie, Justus-Liebig Universität Giessen, \\ IFZ - Heinrich-Buff-Ring 26-32, D-35392 Giessen, Germany
}

\begin{abstract}
A yellow-pigmented bacterial strain $\left(\mathrm{CC}-\mathrm{H} 3-2^{\top}\right)$, isolated from the rhizosphere of Lactuca sativa L. (garden lettuce) in Taiwan, was investigated using a polyphasic taxonomic approach. The cells were Gram-negative, rod-shaped and non-spore-forming. Phylogenetic analyses using the 16S rRNA gene sequence of the isolate indicated that the organism belongs to the genus Chryseobacterium, with the highest sequence similarity to the type strains of Chryseobacterium indoltheticum (97.7\%), Chryseobacterium scophthalmum (97.5\%), Chryseobacterium joostei $(97 \cdot 2 \%)$ and Chryseobacterium defluvii $(97 \cdot 2 \%)$. The major whole-cell fatty acids were iso- $\mathrm{C}_{15: 0}$ $(52 \cdot 2 \%)$ and iso- $\mathrm{C}_{17: 0} 3-\mathrm{OH}$. DNA-DNA hybridization experiments revealed levels of only $27 \cdot 4 \%$ to C. scophthalmum, $27 \cdot 1 \%$ to C. indoltheticum, $14 \cdot 1 \%$ to C. joostei and $7 \cdot 8 \%$ to C. defluvii. DNA-DNA relatedness and biochemical and chemotaxonomic properties demonstrate that strain $\mathrm{CC}-\mathrm{H} 3-2^{\top}$ represents a novel species, for which the name Chryseobacterium formosense sp. nov. is proposed. The type strain is CC-H3-2 $2^{\top}\left(=\right.$ CCUG $49271^{\top}=$ CIP $\left.108367^{\top}\right)$.
\end{abstract}

At the time of writing, the genus Chryseobacterium comprises ten species: Chryseobacterium balustinum, Chryseobacterium gleum, Chryseobacterium indologenes, Chryseobacterium indoltheticum, Chryseobacterium meningosepticum, Chryseobacterium miricola, 'Chryseobacterium proteolyticum' (name not validly published), Chryseobacterium scophthalmum, Chryseobacterium joostei and Chryseobacterium defluvii. These species and the taxonomy of the genus have been extensively described in recently published papers (Hugo et al., 2003; Li et al., 2003; Kämpfer et al., 2003).

Although several strains of Chryseobacterium species have recently been well characterized with regard to their ability to produce heat-stable metalloproteases and proteindeamidating enzymes (Venter, 1987; Yamaguchi \& Yokoe, 2000), their functional role in agricultural soil or plant growth promotion remains largely unclear. While screening for proteolytic activity on skimmed milk agar, five different rhizobacteria from Lactuca sativa L. (garden lettuce) were selected that showed strong proteolytic

Published online ahead of print on 4 October 2004 as DOI 10.1099/ ijs.0.63331-0.

The GenBank/EMBL/DDBJ accession number for the 16S rRNA gene sequence of strain $\mathrm{CC}-\mathrm{H} 3-2^{\top}$ is $\mathrm{AY} 315443$. activities. An additional isolate from the rhizosphere of Lactuca sativa L. from Kuohsing, Taiwan, revealed a yellow pigmentation on nutrient agar. This strain $\left(\mathrm{CC}-\mathrm{H} 3-2^{\mathrm{T}}\right)$ was maintained and subcultivated on brain heart infusion agar at $30^{\circ} \mathrm{C}$ for $48 \mathrm{~h}$ and subsequently investigated via $16 \mathrm{~S}$ rRNA gene sequence analysis. We determined the fatty acid methyl ester composition of whole cell hydrolysates, further phenotypic characteristics [carbon source utilization, API ZYM enzyme profiles (bioMérieux), API 20E tests (bioMérieux)] and DNA-DNA relatedness to those species most closely related on the basis of $16 \mathrm{~S}$ rRNA gene sequence similarity.

Cultural and morphological characteristics were observed on nutrient agar and brain heart infusion agar. Flexirubinlike pigments were observed by flooding the plates with $20 \%$ (w/v) potassium hydroxide (Fautz \& Reichenbach, 1980). Gram reaction was tested by the modified method of Cowan (1974) and motility was tested microscopically from cells grown for 3 days in motility broth at $30^{\circ} \mathrm{C}$ (Cowan, 1974). Fluorescence was tested after plating on King's B medium after 48 h (Cowan, 1974).

Strain CC-H3-2 ${ }^{\mathrm{T}}$ was Gram-negative and formed visible (about $2 \mathrm{~mm}$ ) yellowish colonies after $48 \mathrm{~h}$ growth at $30{ }^{\circ} \mathrm{C}$. No growth was observed above $37^{\circ} \mathrm{C}$, whereas very small colonies were visible after prolonged incubation at 
$15^{\circ} \mathrm{C}$. Within $48 \mathrm{~h}$ at $20^{\circ} \mathrm{C}$, clear, visible colonies appeared. The colonies were translucent and shiny with entire edges, but on prolonged incubation the colonies were not visible as single entities, probably owing to the profuse production of extracellular substances. A bright yellow, non-diffusible, non-fluorescent flexirubin pigment was produced on nutrient agar. Oxidase activity was tested using oxidase reagent (bioMérieux) according to the manufacturer's instructions. Cells of strain CC-H3-2 ${ }^{\mathrm{T}}$ were oxidasepositive, non-motile, non-spore-forming rods $(1 \mu \mathrm{m}$ wide, $2 \mu \mathrm{m}$ long). Strain CC-H3-2 ${ }^{\mathrm{T}}$ was able to grow well on nutrient agar, trypticase soy agar and brain heart infusion agar but was unable to grow on MacConkey's agar.

Physiological characterization and additional biochemical tests were performed to assess the pattern of carbon source utilization and hydrolysis of 19 substrates using the API ZYM system and API 20E according to the methods outlined by the manufacturer (bioMérieux).

Analysis of the cellular fatty acid composition (method as described by Kämpfer et al., 2003) showed that iso- $C_{15: 0}$ was the most abundant fatty acid $(52 \cdot 2 \%)$ followed by iso- $\mathrm{C}_{17: 0} 3-\mathrm{OH}(10.9 \%)$ and summed feature 4 (iso- $\mathrm{C}_{15: 0}$ $\left.2-\mathrm{OH} / \mathrm{C}_{16: 1} \omega 7 t, 6 \cdot 5 \%\right)$. The fatty acid pattern for strain $\mathrm{CC}-\mathrm{H} 3-2^{\mathrm{T}}$ is shown in Table 1 in comparison to all other
Chryseobacterium species. The profile for strain CC-H3-2 ${ }^{\mathrm{T}}$ was typical of Chryseobacterium species, and most similar to that of C. defluvii.

The 16S rRNA gene sequence was amplified by PCR using universal primers $1 \mathrm{~F}$ ( $5^{\prime}$-GAGTTTGATCATGGCTCAG-3') and 7R (5'-TGACGGGCGGTGTGTACAA-3') (Edwards et al., 1989). Sequence analysis was performed using a DNA sequencer (ABI PRISM 310; Applied Biosystems), sequence assembly was performed using the Wisconsin package version 9.1 (GCG, Inc.) with the Fragment Assembly System program supplied by the National Health Research Institute of Taiwan and a phylogenetic tree was constructed using the neighbour-joining method from the distance matrices. Maximum-parsimony and neighbour-joining methods (Fig. 1) were also applied for tree construction.

The nearly full-length (1416 nt) 16S rRNA gene sequence of strain CC-H3-2 $2^{\mathrm{T}}$ was aligned with sequences deposited in GenBank by using CLUSTAL W software available from the European Bioinformatics Institute. Searches indicated that strain CC-H3- $2^{\mathrm{T}}$ was phylogenetically closely related to species of the genus Chryseobacterium. The most closely related species was $C$. indoltheticum $(97.5 \%)$ followed by C. scophthalmum (97.2\%), C. defluvii (97.2\%), C. joostei

Table 1. Long-chain fatty acid composition of Chryseobacterium species and related bacteria

Taxa: 1, C. formosense sp. nov. $(n=1) ; 2$, C. defluvii $(n=1) ; 3$, C. joostei $(n=11) ; 4$, C. gleum $(n=5)$; , C. indologenes ( $n=45)$; 6, C. balustinum $(n=1) ; 7$, C. indoltheticum $(n=1) ; 8$, C. scophthalmum $(n=2) ; 9$, C. meningosepticum $(n=1) ; 10$, C. miricola ( $n=1) ; 11$, Bergeyella zoohelcum $(n=1)$; 12, Empedobacter brevis $(n=6)$. All strains identified as C. gleum, $C$ indologenes and Empedobacter brevis in an earlier study (Hugo et al., 2003) were included. Fatty acids amounting to less than $1 \%$ of the total fatty acids in all strains were not included. Values are given as means \pm SD. tr, Trace (less than 1.0\%); ND, not detected. Data from Kämpfer et al. (2003), Hugo et al. (2003) and Li et al. (2003).

\begin{tabular}{|c|c|c|c|c|c|c|c|c|c|c|c|c|}
\hline Fatty acid & 1 & 2 & 3 & 4 & 5 & 6 & 7 & 8 & 9 & 10 & 11 & 12 \\
\hline Unknown $13 \cdot 566^{\star}$ & $\operatorname{tr}$ & $\operatorname{tr}$ & $1 \cdot 1 \pm 0 \cdot 2$ & $1 \cdot 2 \pm 0 \cdot 4$ & $2 \cdot 1 \pm 0 \cdot 7$ & $1 \cdot 6$ & $1 \cdot 7$ & $2 \cdot 9 \pm 0 \cdot 2$ & $1 \cdot 5$ & $\operatorname{tr}$ & $1 \cdot 8$ & $1 \cdot 9 \pm 1 \cdot 4$ \\
\hline iso- $\mathrm{C}_{15: 0} 3-\mathrm{OH}$ & $1 \cdot 8$ & $2 \cdot 6$ & $2 \cdot 9 \pm 0 \cdot 3$ & $2 \cdot 5 \pm 0 \cdot 1$ & $2 \cdot 6 \pm 0 \cdot 2$ & $2 \cdot 7$ & $2 \cdot 3$ & $2 \cdot 7 \pm 0 \cdot 1$ & $3 \cdot 5$ & 3 & $3 \cdot 95$ & $4 \cdot 8 \pm 0 \cdot 7$ \\
\hline anteiso- $\mathrm{C}_{15: 0}$ & $2 \cdot 1$ & $3 \cdot 2$ & $\operatorname{tr}$ & $\operatorname{tr}$ & $\operatorname{tr}$ & $\operatorname{tr}$ & $5 \cdot 9$ & $\operatorname{tr}$ & $2 \cdot 3$ & $\operatorname{tr}$ & ND & $\operatorname{tr}$ \\
\hline iso- $\mathrm{C}_{16: 0} 3-\mathrm{OH}$ & $1 \cdot 1$ & $\operatorname{tr}$ & ND & ND & ND & $\operatorname{tr}$ & $1 \cdot 3$ & $\mathrm{ND}$ & $\operatorname{tr}$ & $\operatorname{tr}$ & $\mathrm{ND}$ & $\operatorname{tr}$ \\
\hline Unknown $16 \cdot 580^{*}$ & $1 \cdot 0$ & ND & $1 \cdot 6 \pm 0 \cdot 1$ & $1 \cdot 7 \pm 0 \cdot 1$ & $1 \cdot 7 \pm 0 \cdot 2$ & $1 \cdot 3$ & $1 \cdot 3$ & $1 \cdot 5 \pm 0 \cdot 1$ & $1 \cdot 7$ & $\operatorname{tr}$ & $1 \cdot 4$ & $1 \cdot 4 \pm 0 \cdot 1$ \\
\hline $\mathrm{C}_{17: 0} 2-\mathrm{OH}$ & $\mathrm{ND}$ & $\mathrm{ND}$ & $\mathrm{ND}$ & ND & ND & $\operatorname{tr}$ & $3 \cdot 0$ & $\operatorname{tr}$ & $\operatorname{tr}$ & ND & $\mathrm{ND}$ & $\operatorname{tr}$ \\
\hline iso- $\mathrm{C}_{17: 0}$ & $2 \cdot 3$ & $2 \cdot 0$ & $\operatorname{tr}$ & $1 \cdot 6 \pm 0 \cdot 6$ & $\operatorname{tr}$ & $1 \cdot 0$ & $\operatorname{tr}$ & $\operatorname{tr}$ & $\operatorname{tr}$ & 1 & $\mathrm{ND}$ & $\operatorname{tr}$ \\
\hline iso- $\mathrm{C}_{17: 0} 3-\mathrm{OH}$ & $10 \cdot 9$ & $14 \cdot 1$ & $20 \cdot 1 \pm 1 \cdot 2$ & $21 \cdot 8 \pm 0 \cdot 3$ & $19 \cdot 2 \pm 1 \cdot 8$ & $16 \cdot 8$ & $14 \cdot 0$ & $16 \cdot 3 \pm 0 \cdot 1$ & $16 \cdot 3$ & 40 & $13 \cdot 5$ & $17 \cdot 1 \pm 2 \cdot 1$ \\
\hline
\end{tabular}

${ }^{*}$ Unknown fatty acid; numbers indicate equivalent chain length.

$\dagger$ Fatty acids that could not be separated by GC using the Microbial Identification System (Microbial ID) software were considered summed features. Summed feature 4 contains iso- $\mathrm{C}_{15: 0} 2-\mathrm{OH}$ and/or $\mathrm{C}_{16: 1} \omega 7 t$; summed feature 5 contains iso- $\mathrm{C}_{17: 1}$ I and/or anteiso- $\mathrm{C}_{17: 1}$ B. 


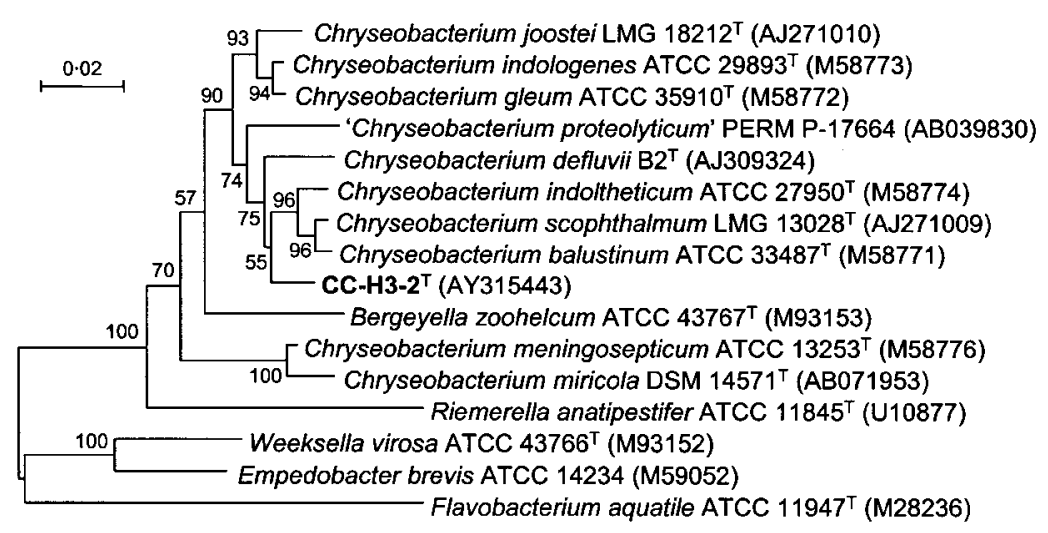

Fig. 1. Phylogenetic analysis based on $16 \mathrm{~S}$ rRNA gene sequences available from the EMBL database (accession numbers are given in parentheses) constructed after multiple alignment of data by CLUSTAL X (Thompson et al., 1997). Distances (distance options according to the Kimura two-parameter model) were determined and clustering with the neighbour-joining method was performed by using the software package MEGA version 2.1 (Kumar et al., 2001). Bootstrap values based on 1000 replications are listed as percentages at branch points. Bar, 0.02 substitutions per nucleotide position.
$(97 \cdot 2 \%)$ and C. indologenes $(97 \cdot 1 \%)$; sequence similarities to all other Chryseobacterium species were below $96 \cdot 8 \%$.

DNA-DNA hybridization experiments were performed with strain CC-H $3-2^{\mathrm{T}}$ and the type strains of the four most closely related Chryseobacterium species using the method described by Ziemke et al. (1998) except that, for nick translation, $2 \mu \mathrm{g}$ DNA was labelled with $3 \mathrm{~h}$ of incubation at $15^{\circ} \mathrm{C}$. Strain $\mathrm{CC}-\mathrm{H} 3-2^{\mathrm{T}}$ showed relatively low levels of DNA-DNA relatedness to the type strains of C. indoltheticum CIP $103168^{\mathrm{T}}(27 \cdot 1 \%$, reciprocal $14 \cdot 1 \%)$,
C. scophthalmum CIP $104199^{\mathrm{T}}(27 \cdot 4 \%, 15 \cdot 7 \%)$, C. joostei CIP $105533^{\mathrm{T}}(14 \cdot 1 \%, 7 \cdot 3 \%)$ and C. defluvii $\mathrm{B}^{\mathrm{T}}(7 \cdot 8 \%)$. Pooled standard deviations of all hybridization experiments were between 8.0 and $11.6 \%$.

Strain CC-H3-2 $2^{\mathrm{T}}$ utilized only a few carbon sources but was able to hydrolyse 11 of 19 compounds in the API ZYM system. Biochemical/physiological characteristics of the strain are given in Table 2 and under the species description. A striking difference was observed in enzyme activities, especially for $\alpha$-glucosidase and $\beta$-glucosidase.

Table 2. Comparison of characteristics of strain $\mathrm{CC}-\mathrm{H} 3-2^{\top}$ with other recognized Chryseobacterium species

Species/strains: 1, C. formosense sp. nov. CC-H3-2 ${ }^{\mathrm{T}}$; 2, C. defluvii $(n=1) ; 3$, 'C. proteolyticum' $(n=2)$; 4, C. gleum ( $\left.n=12\right)$; 5, C. indologenes $(n=13) ; 6$, C. balustinum $(n=1) ; 7$, C. indoltheticum $(n=1) ; 8$, C. meningosepticum $(n=49)$; 9, C. scophthalmum ( $n=7)$; 10, C. joostei $(n=11)$; 11, C. miricola $(n=1)$. Data for reference species were taken from Kämpfer et al. (2003), Li et al. (2003) and Hugo et al. (2003). + , All strains positive; $(+)$, weakly positive; -, all strains negative; V, variable; NA, not available; two figures separated by a solidus (/) refer to the number of positive strains/number of strains tested.

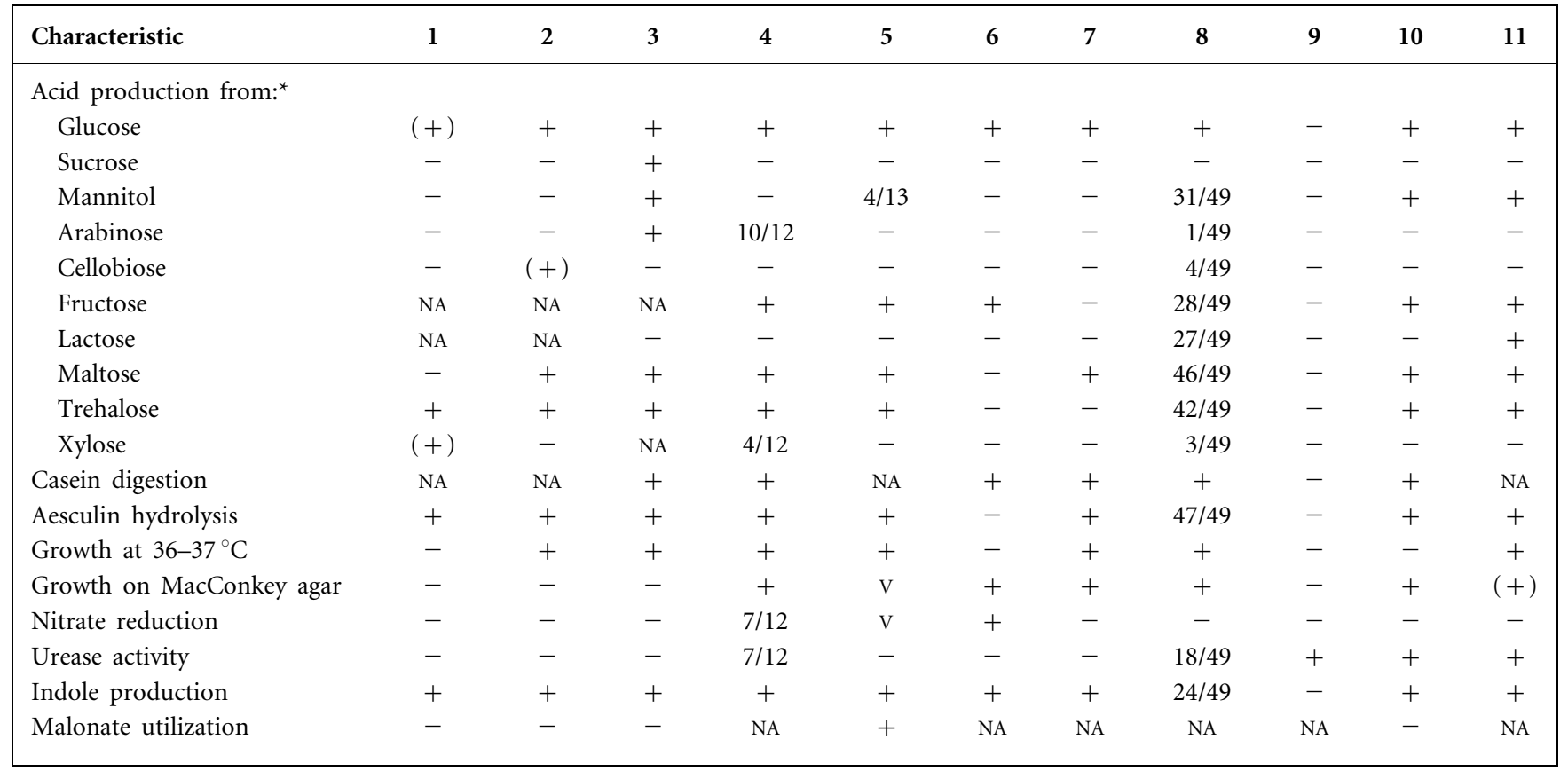

*The methods for testing acid formation from different sugars are different. Readers should refer to the original references for direct comparisons. 
C. defluvii and C. scophthalmum were positive for $\alpha$ glucosidase but were negative for $\beta$-glucosidase activity whereas strain CC-H $3-2^{\mathrm{T}}$ was positive for $\beta$-glucosidase and negative for $\alpha$-glucosidase activity.

On the basis of the results of this polyphasic study, it is evident that strain CC-H3-2 $2^{\mathrm{T}}$ represents a novel species of the genus Chryseobacterium, for which the name Chryseobacterium formosense sp. nov. is proposed.

\section{Description of Chryseobacterium formosense sp. nov.}

Chryseobacterium formosense [for.mo.sen'se. N.L. neut. adj. formosense pertaining to Formosa (Taiwan)].

Cells are Gram-negative, non-motile, non-spore-forming rods (about $2 \mu \mathrm{m}$ in length and $1 \mu \mathrm{m}$ wide). Aerobic, oxidase-positive, with good growth after $48 \mathrm{~h}$ on trypticase soy agar, brain heart infusion agar and nutrient agar at $25-32^{\circ} \mathrm{C}$, but unable to grow on MacConkey's agar. Colonies on nutrient agar are smooth, yellowish, circular, translucent and shiny with entire edges; they become mucoid and cannot be identified as single entities after prolonged incubation. Yellow pigmentation is nondiffusible, non-fluorescent of flexirubin type. Unable to grow at $5{ }^{\circ} \mathrm{C}$ or above $37^{\circ} \mathrm{C}$. Major cellular fatty acids are iso- $\mathrm{C}_{15: 0}$ and iso- $\mathrm{C}_{17: 0} 3-\mathrm{OH}$. Positive for indole and acetoin production, gelatinase and cytochrome oxidase activity, but negative for $\beta$-galactosidase, arginine dihydrolase, lysine decarboxylase, citrate utilization, $\mathrm{H}_{2} \mathrm{~S}$ production, urease, tryptophan deaminase and oxidation of glucose, mannitol, inositol, sorbitol, rhamnose, sucrose, melibiose, amygdalin and arabinose. The following compounds are utilized as sole carbon sources: dextrin, Darabitol, lactulose, acetic acid, D-sorbitol, sucrose, turanose, xylitol, citric acid, D-gluconic acid, D-glucosaminic acid, DL-lactic acid, quinic acid, succinamic acid, L-alaninamide, L-pyroglutamic acid (all weakly positive), cellobiose, gentiobiose, $\alpha$-D-glucose, maltose, D-mannose, L-rhamnose, D-trehalose, monomethyl succinate, D-galacturonic acid, $\alpha$ ketobutyric acid, $\alpha$-ketovaleric acid, DL-alanine, L-alanyl glycine, L-asparagine, L-aspartic acid, L-glutamic acid, glycyl L-aspartic acid, glycyl L-glutamic acid, L-leucine, Lornithine, L-phenylalanine, L-proline, L-serine, L-threonine, inosine, uridine, thymidine, glucose 1-phophate and glucose 6-phosphate. The following are not utilized as sole carbon sources: methyl $\beta$-D-glucoside, D-raffinose, propionic acid, cyclodextrin, glycogen, Tweens 40 and $80, \mathrm{~N}$-acetylD-galactosamine, $\mathrm{N}$-acetyl-D-glucosamine, adonitol, Larabinose, $i$-erythritol, D-fructose, L-fucose, D-galactose, $m$-inositol, $\alpha$-D-lactose, D-mannitol, D-melibiose, D-psicose, methylpyruvate, cis-aconitic acid, formic acid, D-galactonic acid lactone, D-glucuronic acid, $\alpha$-, $\beta$ - and $\gamma$-hydroxybutyric acid, $p$-hydroxyphenylacetic acid, itaconic acid, $\alpha$-ketoglutaric acid, malonic acid, D-saccharic acid, sebacic acid, succinic acid, bromosuccinic acid, glucuronamide, Dalanine, L-histidine, hydroxyproline, D-serine, DL-carnitine, $\gamma$-aminobutyric acid, urocanic acid, phenylethylamine, putrescine, 2-aminoethanol, 2,3-butanediol, glycerol and DL- $\alpha$-glycerol phosphate. Positive enzyme activities are seen for alkaline phosphatase, butyrate esterase, caprylate esterase, leucine arylamidase, valine arylamidase, cystine arylamidase, trypsin, acid phosphatase, naphthol-AS-BIphosphohydrolase, $\beta$-glucosidase and $N$-acetyl- $\beta$-glucosaminidase, but negative for myristate lipase, $\alpha$-chymotrypsin, $\alpha$-galactosidase, $\beta$-galactosidase, $\beta$-glucuronidase, $\alpha$-glucosidase, $\alpha$-mannosidase and $\alpha$-fucosidase.

The type strain, CC-H3-2 ${ }^{\mathrm{T}}\left(=\mathrm{CCUG} 49271^{\mathrm{T}}=\mathrm{CIP} 108367^{\mathrm{T}}\right)$, was isolated from the rhizosphere of Lactuca sativa $\mathrm{L}$. (garden lettuce).

\section{Acknowledgements}

We thank Dr J.-F. Bernardet, INRA, France, for kindly providing us with the type strain of C. scophthalmum and for his constructive suggestions. This research was supported by a grant from the National Science Council and the Council of Agriculture, Executive Yuan, Taiwan, Republic of China.

\section{References}

Cowan, S. T. (1974). Cowan and Steel's Manual for the Identification of Medical Bacteria, 2nd edn. Cambridge: Cambridge University Press.

Edwards, U., Rogall, T., Blocker, H., Emde, M. \& Bottger, E. C. (1989). Isolation and direct complete nucleotide determination of entire genes. Characterization of a gene coding for $16 \mathrm{~S}$ ribosomal RNA. Nucleic Acids Res 17, 7843-7853.

Fautz, E. \& Reichenbach, H. (1980). A simple test for flexirubin-type pigments. FEMS Microbiol Lett 8, 87-91.

Hugo, C. J., Segers, P., Hoste, B., Vancanneyt, M. \& Kersters, K. (2003). Chryseobacterium joostei sp. nov., isolated from the dairy environment. Int J Syst Evol Microbiol 53, 771-777.

Kämpfer, P., Dreyer, U., Neef, A., Dott, W. \& Busse, H.-J. (2003). Chryseobacterium defluvii sp. nov., isolated from wastewater. Int J Syst Evol Microbiol 53, 93-97.

Kumar, S., Tamura, K., Jakobsen, I. B. \& Nei, M. (2001). MEGA2: molecular evolutionary genetics analysis software. Bioinformatics 17, 1244-1245.

Li, Y., Kawamura, Y., Fujiwara, N., Naka, T., Liu, H., Huang, X., Kobayashi, K. \& Ezaki, T. (2003). Chryseobacterium miricola sp. nov., a novel species isolated from condensation water of space station Mir. Syst Appl Microbiol 26, 523-528.

Thompson, J. D., Gibson, T. J., Plewniak, F., Jeanmougin, F. \& Higgins, D. G. (1997). The CLUSTAL_X windows interface: flexible strategies for multiple sequence alignment aided by quality analysis tools. Nucleic Acids Res 25, 4876-4882.

Venter, H. (1987). Purification and characterization of a heat stable metalloprotease from a Chryseobacterium of dairy origin. MSc thesis, University of Orange Free State, Bloemfontein, South Africa.

Yamaguchi, S. \& Yokoe, M. (2000). A novel protein-deamidating enzyme from Chryseobacterium proteolyticum sp. nov., a newly isolated bacterium from soil. Appl Environ Microbiol 66, 3337-3343.

Ziemke, F., Höfle, M. G., Lalucat, J. \& Rosselló-Mora, R. (1998). Reclassification of Shewanella putrefaciens Owen's genomic group II as Shewanella baltica sp. nov. Int J Syst Bacteriol 48, 179-186. 